$$
\begin{aligned}
& \text { مؤثرات التبعية الاقتصادية والغذائية لأهم محاصيل الحبوب في مصر } \\
& \text { نشوى عبد الحميد النطاوى ، شيرين أحمد شريف1 ، مي مصطفى حسن مرسي 1 ، سمر ثابت زاكي مختار } 1
\end{aligned}
$$

على مصر. كما تساهم صادرات الأرز بنحو 8\% من الصادرات

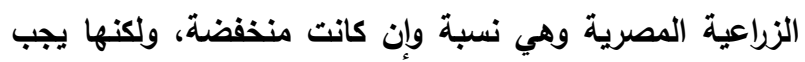
أن تؤخذ في الاعتبار، وتأتي سوريا في المرتبة الأولى بنسبة بلغت نحو 19\% مما يعني يجعل يرفع فرص سيادة مصر عليها، يليها تركيا بنسبة بلغت نحو 12\%، وفي وفي المرتبة الأخيرة دولة

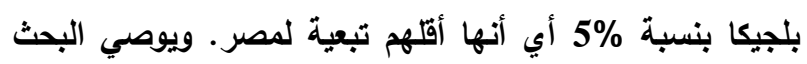

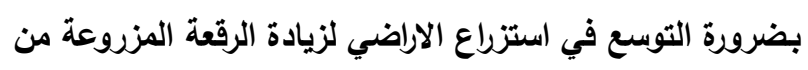

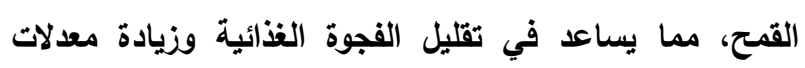

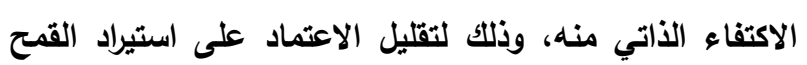

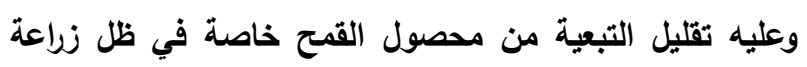

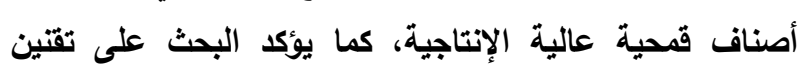

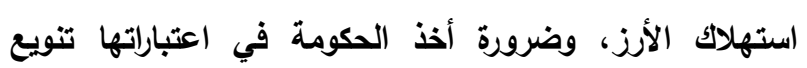

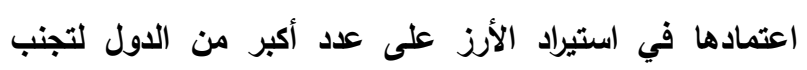
ضغوط الأسواق في بعض البلان البان المصدرة وتحقيق أهداف الأمن التئن

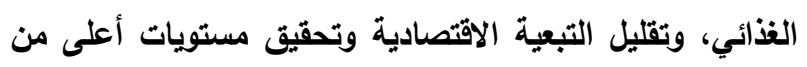

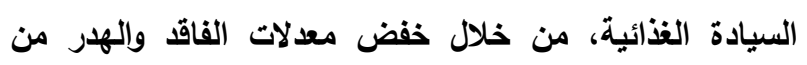
مصصولي القمح والارز خاصة خلال الجمع والتعبئة والنقل وإلتخزين.

الكلمات الادلة: التبعية الاقتصادية- التبعية الغذائيةالقمح- الأرز - السيادة الغذائية.

\section{المقدمة}

يعتبر تحقيق السيادة الغذائية كمرادف للأمن الغذائي تعزيز لتحقيق الهدف الثاني من الأهداف الإنمائية للأكم

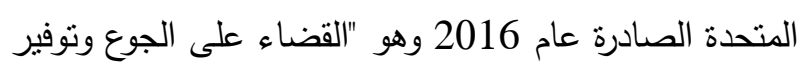
الأمن الغذائي والتغذية المحسنة وتعزيز الزراعة المستدامة"، وهاءل

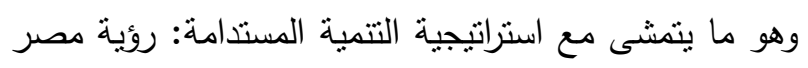
2030 والتي تستهد تقليل الفاقد والهدر من الغذاء وترشيد

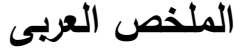

تتضح ملامح التبعية الاقتصادية والثذائية في محصول

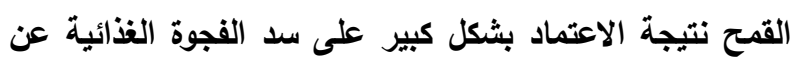

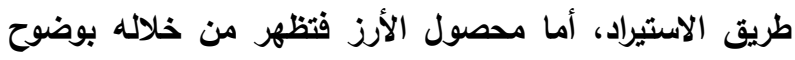

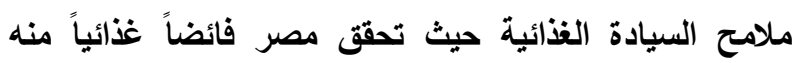

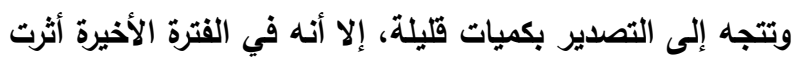

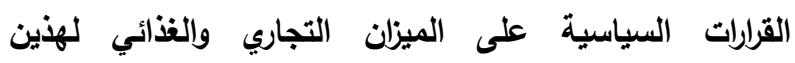
المحصولين مما أثر على مؤثرات التبعية والسيادة الغذائية

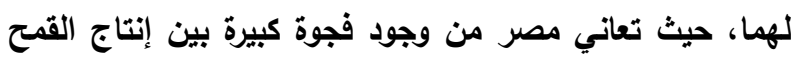

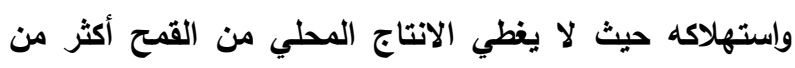

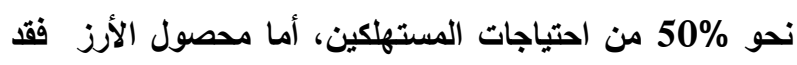

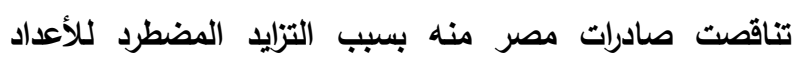

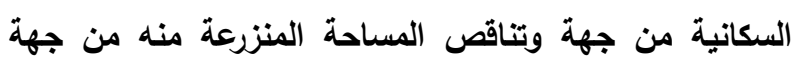

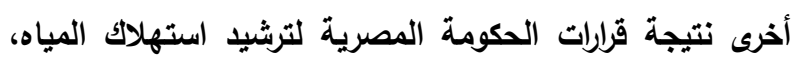
وعليه؛ يستهاف البحث إلقاء الضوء على التبعية الغذائية لأهم التهرية

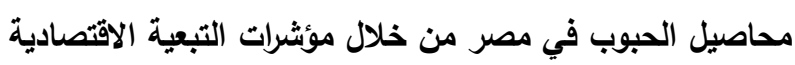

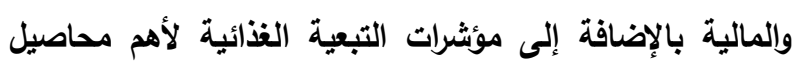

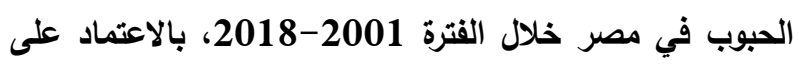
مؤشر الانكثاف الاقتصادي ومؤشر خدمة الاين ومؤشر التركز

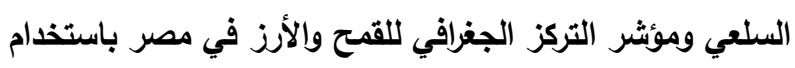

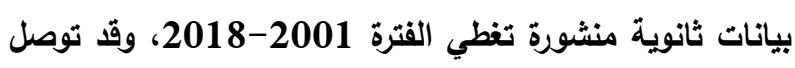
البحث إلى عدد من النتائج يعتبر من أهمها أن واردات القئح

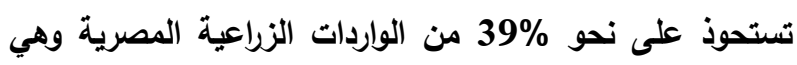

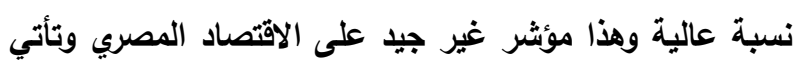

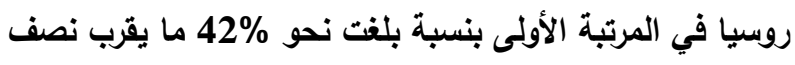

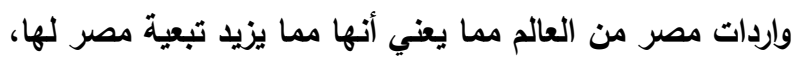

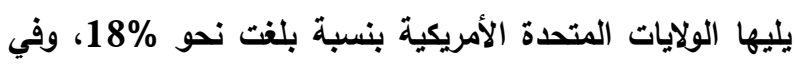
المرتبة الأخيرة دولة استراليا بنسبة 8\% أي أنها أقلهم سيادة

معرف الوثيقة الرقمي: 10.21608/asejaiqjsae.2022.214846 1قسم الاقتصاد الزراعي- كلية الزراعة- جامعة الاسكندرية الرقية

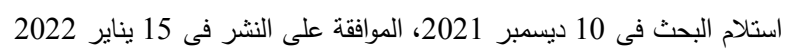




$$
\text { مجلة الإسكندرية للتبادل العلمى - (مجلد } 43 \text { العدد 1) يناير - مارس } 2022
$$

والتي تقوم الدولة بسدها عن طريق الاسنتراد من الأسواق

$$
\text { الخارجية (مختار، 2021). }
$$

ويحتل الأرز مكانة الصدارة في قائمة المحاصيل

الغذائية الضرورية، والتي بعتمد عليها غالبية السكان المصربين في نظامهم الغذائي، ولا يزال هذا المحصول يحقق

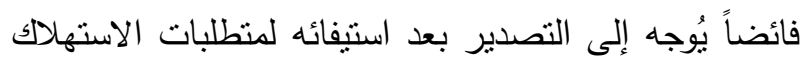

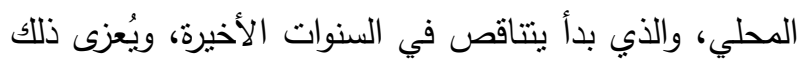
إلى النزايد المضطرد للأعداد السكانية من جهة وتتاقص المساحة المنزرعة منه من جهة أخرى نتيجة قرارات الحكومة المصرية لترشيد استهلاك المياه، مما ترتب عليه تتاقص مله صادرات مصر من الأرز حيث بلغ منوسط كمية الصادرات المصرية من الأرز خلال تلك الفترة حوالي 0.52 مليون طن، في حين بلغ منوسط نسبة الاكتفاء الذاتي منه خلا الفترة 2017-2017 بنحو 111.12\%، وبلغ متوسط حجم الفائض الغذائي من هذا المحصول حوالي 0.44 مليون طن، وبالتالي فإن الإبقاء على تحقيق السيادة الغذائية من محصول الأرز سوف يعتبر تحدياً رئيسياً للأمن الغذائي المصري إنياء والأمن المائي في ذات الوقت (مختار، 2021).

\section{الأهداف البحثية}

انطلاقاً من المشكلة البحثية؛ استهدف البحث بصفة أساسية إلقاء الضوء على التبعية الغذائية لأهم محاصيل الحبوب في مصر من خلال حساب مؤشرات التبعية الاقتصادية والمالية للمقتصد المصري بالإضافة إلى مؤشرات التبعية الغذائية لأهم محاصيل الحبوب في مصر خلال الفترة

$$
\text { .2018-2001 }
$$

\section{الأساليب البحثية ومصادر البيانات}

تحقيقاً لأهداف البحث تم الاعتماد على الأساليب الاقتصادية التحليلية الوصفية والاستدلالية من خلال استخدام بعض الأدوات الإحصائية الوصفية كأساليب العرض الجدولية والبيانية، النسب المئوية والمتوسطات الحسابية والهندسية،
الاستهلاك، وتطوير منظومتي التسويق والإرشاد الزراعي، حيث يعتبر الأمن الغذائي أحد أهداف السياسات الاقتصادية والاجتماعية لأي مقتصد (وزارة التخطيط والإصلاح الإداري، 2015)، وقد أولت استراتيجية التتمية الزراعية 2030 اهتماماً خاصاً لمحور الأمن الغذائي حيث اشتملت رسالة استراتيجية التتمية الزراعية المستدامة 2030 على: "تحديث الزراعة المصرية لتحقيق الأمن الغذائي وتحسين مستوى معيشة السكان الريفيين، وذلك بالارتقاء بكفاءة استخدام الموارد واستثمار كل من مقومات التميز الجغرافي السياسي لمصر من جهة، والمتمايزات البيئية فيما بين الأقاليم الزراعية المصرية من جهة أخرى"، وقد منل تحقيق درجة أعلى للأكن الغذائي من سلع الغذاء الإستراتيجية أحد الأهداف الاستراتيجية للتتمية الزراعية المستدامة 2030. (وزارة الزراعة واستصلاح الأراضي، 2015) يعتبر محصولي القمح والأرز من أهم محاصيل الحبوب في مصر، فبجانب أهميتهما الغذائية للأفراد تظهر أهميتهما الاستراتيجية للدولة، حيث يتضح في محصول القمح ملامح

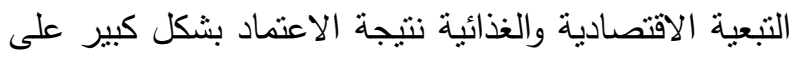
سد الفجوة الغذائية عن طريق الاستيراد، أما محصول الأرز فيظهر بوضوح ملامح السيادة الغذائية حيث تحقق مصر فائضاً غذائياً منه وتتجه إلى التصدير بكميات قليلة، إلا أن القرارات السياسية في القترة الأخيرة أثرت على الميزان التجاري والغذائي لهذين المحصولين مما أثز على مؤشرات

$$
\text { التبعية والسيادة الغذائية لهما. }
$$

\section{المشكلة البحثية}

تعاني مصر من وجود فجوة كبيرة بين إنتاج القمح واستهلاكه حيث لا يغطي الانتاج المحلي من القمح أكثر من من نصف احتياجات المستهلكين، فقد بلغ متوسط نسبة الاكتفاء الذاتي منه خلال الفترة 2017-2001 نحو 53.63\%، وبلغ متوسط حجم الفجوة القمحية نحو 7.30 مليون طن، 
-موئشر عبء خلمة الايون الخارجية في الدولة. ويمكن توضيحه كما بالمعادلة رقم (2). مؤثر عبء خدمة الايون الخارجية

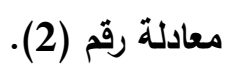

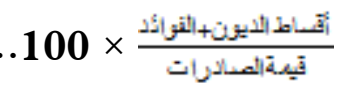

3- التبعية الغذائية: تتطوي التبعية الغذائية على مؤثرين: -مؤثر التركز السلعي: ويتم حسابه لكل من الصادرات والواردات. ويمكن توضيحه بالمعادلتين رقم (3) و (4).

$$
\text { -مؤشثر التركز السلعي للصادرات = }
$$

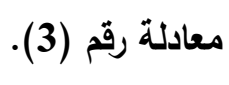

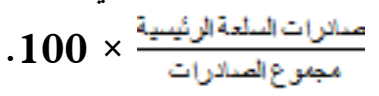
-مؤشر التركز السلعي للواردات =

معادلة رقم (4).

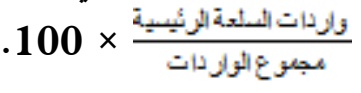

يُعد ارتفاع مؤشر التركز السلعي للصادرات دليلاً حاسماً

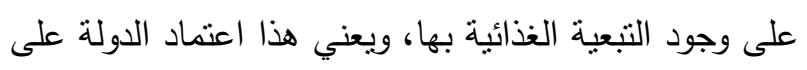
الخارج في تصريف فائض إنتاجها على سلعة أو سلعتين التي تتخصص في تصديرها، وكذلك في الحصول على عديد من السلع الأساسية التي لا تقوم بإنتاجها. - مؤثر التركز الجغرافي: يُقصد به درجة نركيز واردات

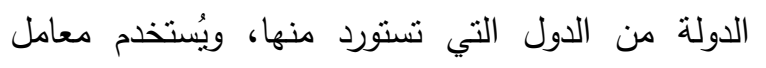
هيرشمان في حساب درجة التركز الجغرافي، ويمكن حسابه وفقاً للمعادلة رقم (5) على النحو التالي: (الفيل

$$
\text { وآخرون،2018) }
$$

- معامل جيني هيرشمان للتركز الجغرافي=

معادلة رقم (5). $100 \sqrt{\Sigma\left[\frac{X i j}{X i}\right]^{2}}$ حيث أن:

Xij: كمية الصادرات أو الواردات من السلعة إلى دولة أخرى. Xi
1-التبعية الأتتصادية: وتنطوي على: درجة الانكشاف الاقتصادي: تبرز أهمية هذا المؤشر في التعرف على مدى مساهمة التجارة الخارجية بشقيها (الصادرات والواردات) في نكوين الناتج المحلي الإجمالي لدولة ما، ويتم حساب المؤشر وفقاً للمعادلة رقم (1):

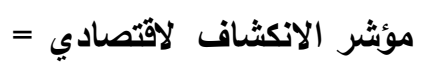

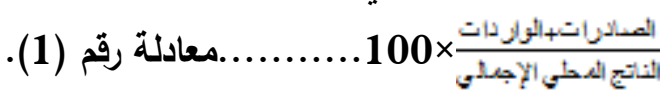

وكلما ارتفعت نسبة المؤشر دل ذلك على ارتفاع مجموع قيمة الصادرات أو الواردات للدولة إلى ناتجها المحلي الإجمالي، وازداد تأثز اقتصادها بالتغيرات في ظروف التجارة

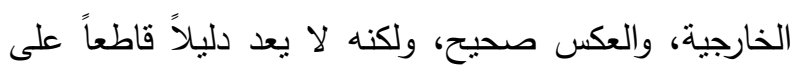
تبعية اقتصاد الدولة للخارج، بل يجب تأكيده بمؤشرات اخري كمؤشر التركز السلعي ومؤشر التركز الجغرافي. 2-التبعية المالية: تعبر التبعية المالية في الدول النامية عن الوجه النقدي لتبعيتها التجارية، وتمنل نتيجة طبيعية لإختلال الهيكل الإنتاجي في اقتصاديات الدول النامية، وقد اشتدت ظاهرة التبعية المالية في الدول النامية في السنوات الأخيرة نتيجة ازدياد حاجة هذه الدول إلى الاستدانة من الدول المتقدمة لتمويل العجز المستمر والمنزايد في موازين مدفعاتها، ذلك هده العجز الناتج عن بطء معدلات نمو صادراتها والارتفاع المستمر والمتزايد في معدلات نمو وارداتها، سواء من السلع الاستهلاكية لمواجهة الزيادة في أعداد السكان بها، فضلاً

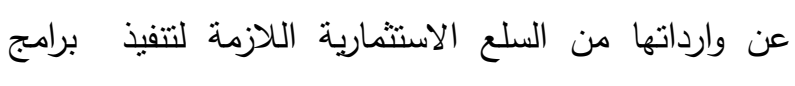
التتمية بها. وقد ترتب على ذلك زيادة مديونيات الدول النامية، ومن ثم تزايد تبعيتها المالية للخارج، التي تقاس بتزايد عبء خدمة ديونها الخارجية، وتتطوي علي: 
حوالي 175.61 مليار دولار خلا الفترة 20012018، وبمعدل نمو سنوي معنوي إحصائيا عند المستوى دالئا

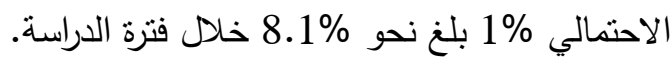
- قيمة الناتج المحلي الاجمالي الزراعي: تراوح الناتج المحلي الاجمالي الزراعي بين حد أدنى بلغ حوالي

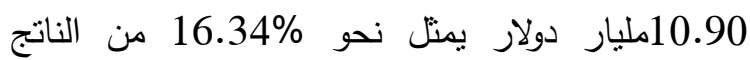

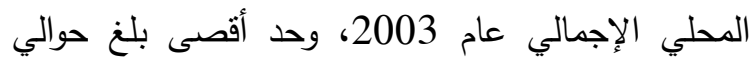
36.20 مليار دولار يمثل نحو $11.26 \%$ من الناتج المحلي الإجمالي عام 2015، وقد بلغ المنوسط حوالي 22.31 مليار دولار خلال الفترة 2001-2018، وبمعدل نمو سنوي معنوي إحصائيا عند المستوى الاحتمالي \% 1 بلغ نحو \% 5.7 خلال فترة الدراسة. - قيمة الصادرات الكلية: تراوحت قيمة الصادرات الكلية بين

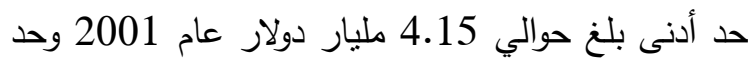
أقصى بلغ حوالي 31.55مليار دولار عام 2011، في دالي حين بلغ المتوسط السنوي حوالي 20.04 مليار دولار خلال الفترة 2001-2018، وبمعدل نمو سنوي معنوي إحصائيا عند المستوى الاحتمالي 1\% بلغ نحو 111\%

خلال فترة الدراسة.

- قيمة الصادرات الزراعية: تراوحت قيمة الصادرات الزراعية بين حد أدنى بلغ حوالي 0.53 مليار دولار بمنل نحو 12.79\% من الصادرات الكلية عام 2001 وحد

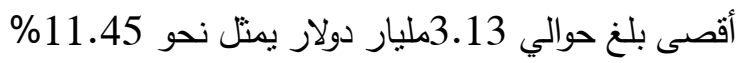
من الصادرات الكلية عام 2010، في حين بلغ المتوسط السنوي حوالي 2.03 مليار دولار خلا الفترة 20012018، وبمعدل نمو سنوي معنوي إحصائيا عند المستوى دائول الاحتمالي \% 1 بلغ حوالي \% 10.2 خلال فترة الدراسة.
ويفيد حساب درجة التركز في التوزيع الجغرافي للواردات

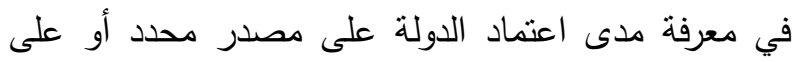

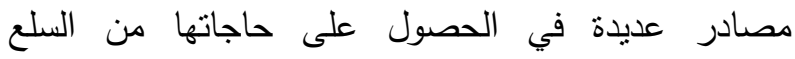
المستورد، ويمكن القول أنه كلما انخفضت درجة التركز

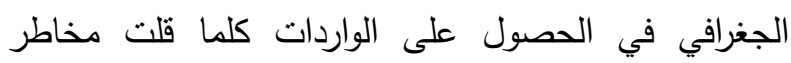
التبعية الناتجة عن الاعتماد على مصادر متعددة، والعكس صحيح، حيث أن ارتفاع درجة التركز الجغرافي للواردات

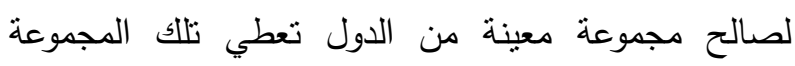

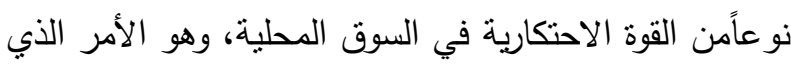

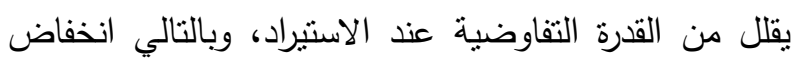
كفاءة الاستيراد لدي الدولة المستوردة.(عجمية،2009) ويصل هذا المعامل إلى أقصى قيمة له ونساوي 100 درجة في حالة ما إذا كان يتم تصدير السلعة إلى سوق واحد

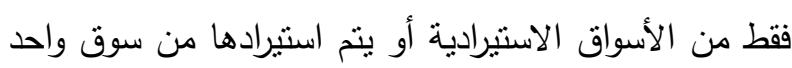
فقط من الأسواق التصديرية، بينما نقل تلك القيمة كلما

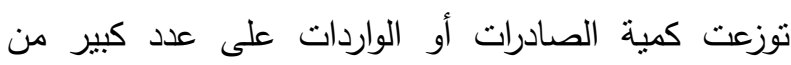

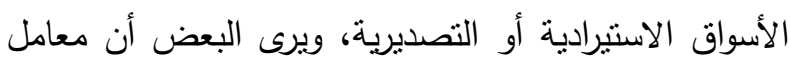
التزكز الجغرافي يُعد مرتفعاً إذا كانت قيمته أكبر من 40 درجة، حيث يعني ذلك احتمال حدوث تقلبات كمية شديدة نسبياً خاصة في قيمة الصادرات.

\section{النتائج البحثية}

أولاً: المؤثرات الاقتصادية والمالية للمقتصد المصري: بدراسة أهم المؤشرات الاقتصادية والمالية في المقتصد المصري خلال الفترة 2001-2018، يتضح من نتائج

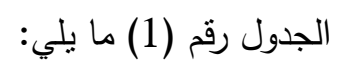

- قيمة الناتج المحلي الاجمالي: تراوح الناتج المحلي الاجمالي الكلي بين حد أدنى بلغ نحو 66.76 مليار دولار عام 2003 وحد أقصى بلغ حوالي 321.55 مليار دولار عام 2015، في حين بلغ المتوسط السنوي 
جدول 1. أهم المؤشرات الاقتصادية والمالية للمقتصد المصري خلال الفترة (2001-2018)

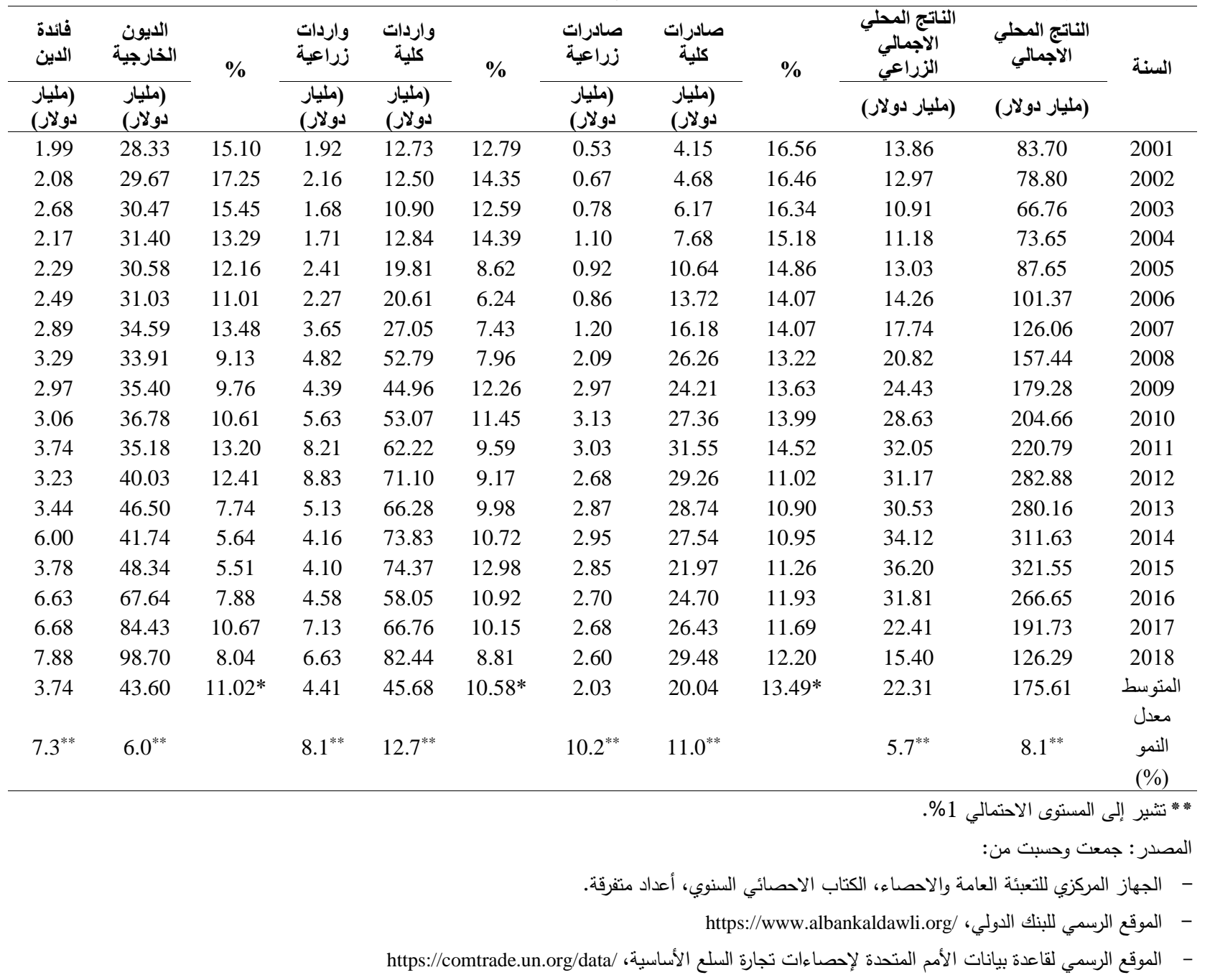

بلغ حوالي 8.83 مليار دولار يمثل نحو 12.41\% من الواردات الكلية عام 2002، في حين بلغ المتوسط السنوي حوالي 4.41 مليار دولار خلال الفترة 20012018، وبمعدل نمو سنوي معنوي إحصائيا عند المستوى موري

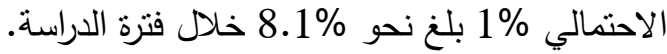
- قيمة الديون الخارجية: تراوحت الديون الخارجية بين حد أدنى بلغ حوالي 28.33 مليار دولار عام 2001 وحد أقصى بلغ حوالي 98.70 مليار دولار عام 2018، في دولي حين بلغ المتوسط السنوي حوالي 43.60 مليار دولار خلال الفترة 2001-2018، وبمعدل نمو سنوي معنوي
- قيمة الواردات الكلية: تراوحت قيمة الواردات الكلية بين حد أدنى بلغ حوالي 10.90 مليار دولار عام 2003 وحد أقصى بلغ حوالي 82.44مليار دولار عام 2018، في حين بلغ المنوسط السنوي حوالي 45.68 مليار دولار خلال الفترة 2001-2018، وبمعدل نمو سنوي معنوي إحصائيا عند المستوى الاحتمالي 1\% بلغ نحو 12.7\% خلال فترة الدراسة. - قيمة الواردات الزراعية: تراوحت الواردات الزراعية بين حد أدنى بلغ حوالي 1.68 مليار دولار يمثل نحو

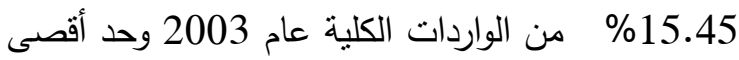


المحلي الاجمالي الزراع خلال فنرة الدراسة، بما يؤكد انكشاف القطاع الزراعي للخارج وتأثره بالتذبذبات الحادثة في التجارة الخارجية الزراعية بنسبة كبيرة نوعاً ما. 2- مؤثرات التبعية المالية: - مؤشر خدمة الدين: تراوح مؤثر خدمة الدين بين حد أدنى موسرائ بلغ نحو 123.36\% عام 2011 وحد أقصى بلغ نحو مونر 731.50\% عام 2001، بمتوسط هندسي بلغ نحو 261.45\% خلال الفترة 2001-2018، مما بعني أن ديون الدولة تفوق قيمة الصادرات بنسبة تمثل نحو 261\%، وهذا مؤشر غير جيد على الاقتصاد المصري، حيث يثير إلى ارتفاع التبعية المالية للمقتصد المصري.

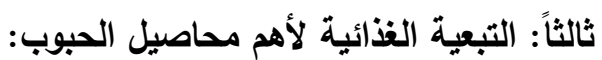
بالإشارة إلى قيمة واردات القمح وقيمة صادرات الأرز في مصر خلال الفترة 2001-2018، اتضح من بيانات جدول

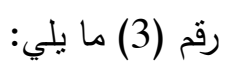

- قيمة واردات القمح المصرية: نراوحت قيمة واردات القمح بين حد أدنى بلغ حوالي 0.61 مليار دولار عام 2003 وحد أقصى بلغ حوالي 3.20 مليار دولار عامي 2011 و2012، بمتوسط سنوي بلغ حوالي 1.81 مليار دولار خلال الفترة 2001-2018، وبمعدل نمو سنوي معنوي إحصائيا عند المستوى الاحتمالي 1\% خلال فترة الدراسة. - قيمة صادرات الأرز المصرية: نراوحت قيمة صادرات الأرز بين حد أدنى بلغ حوالي 0.02 مليار دولار عامي 2011 و 2016، وحد أقصى بلغ حوالي 0.48 مليار دولار عام 2009، بمتوسط سنوي بلغ حوالي 0.17 مليار دولار خلال الفترة 2001-2018، وبمعدل نتاقص حلع سنوي معنوي إحصائيا عند المستوى الاحتمالي 1\% بلغ نحو 16\% خلال فترة الدراسة.
إحصائيا عند المستوى الاحتمالي 1\% بلغ نحو خلال فترة الدراسة. - قيمة فائدة الديون: تراوحت فائدة الديون بين حد أدنى بلغ حوالي 1.99 مليار دولار عام 2001 وحد أقصى بلغ حوالي 7.88مليار دولار عام 2018، في حين بلغ المتوسط السنوي حوالي 3.74 مليار دولار خلا الفيل الفترة 2001-2018، وبمعدل نمو سنوي معنوي إحصائيا عند المستوى الاحتمالي 1\% بلغ نحو 1.3 \% خلال فترة الاراسة.

ثانياً: التبعية الاقتصادية والمالية المصرية: تتعكس التبعية الاقتصادية سلباً على الأمن القومي بصفة عامة والأمن الغذائي بصفة خاصة، فلم تعد مشكلة الغذاء قاصرة على القطاع الزراعي فقط، وفيما يلي عرضاً لأهم

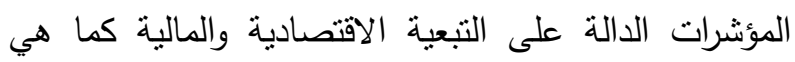
موضحة بالجدول رقم (2). 1-مؤشرات التبعية الاقتصادية في مصر: بـ

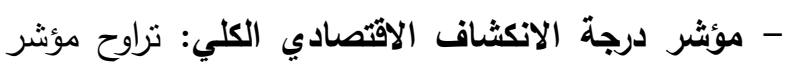
درجة الانكثاف الاقتصادي الكلي بين حد أدنى بلغ نحو لرجه 88.62\% 20.16\% عام 2001 وحد أقصى بلغ نحو

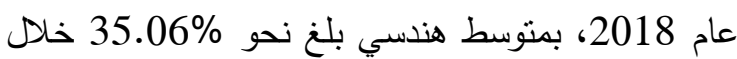
الفترة 2001-2018، مما بعني أن التجارة الخارجية الكلية منلت نحو 35\% من الناتج المحلي الاجمالي الكلي خلال فترة الدراسة، وهي نسبة مرتفعة نسبياً تعني تأثز الاقتصاد بنسبة كبيرة نسبياً بالتجارة الخارجية

\section{وتغيراتها.}

- مؤثر درجة الانكشاف الاقتصادي الزراعي: تراوح مؤشر

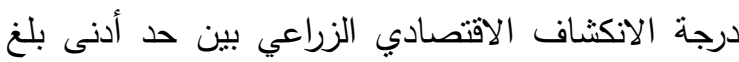
نحو 17.69\% عام 2001 وحد أقصى بلغ نحو 59.89\% عام 2016، بمتوسط هندسي بلغ نحو 27.54\% خلال الفترة 2001-2018، مما يعني أن التجارة الخارجية الزراعية مثلت نحو 27\% من الناتج 
جدول 2. مؤثر درجة الانكثاف الاقتصادي الكلي والززاعي ومؤثثر خدمة الدين في مصر خلال الفترة (2001-2018)

\begin{tabular}{|c|c|c|c|}
\hline مؤشر خدمة الدين & مؤشر درجة الانكشاف الاقتصادي الزراعي & مؤشر درجة الانكشاف الاقتصادي الكلي & السنة \\
\hline 731.50 & 17.69 & 20.16 & 2001 \\
\hline 678.74 & 21.79 & 21.80 & 2002 \\
\hline 537.49 & 22.55 & 25.57 & 2003 \\
\hline 437.38 & 25.14 & 27.86 & 2004 \\
\hline 308.77 & 25.53 & 34.74 & 2005 \\
\hline 244.35 & 21.91 & 33.86 & 2006 \\
\hline 231.69 & 27.34 & 34.30 & 2007 \\
\hline 141.69 & 33.19 & 50.21 & 2008 \\
\hline 158.49 & 30.11 & 38.58 & 2009 \\
\hline 145.63 & 30.61 & 39.30 & 2010 \\
\hline 123.36 & 35.06 & 42.47 & 2011 \\
\hline 147.83 & 36.92 & 35.48 & 2012 \\
\hline 173.79 & 26.20 & 33.91 & 2013 \\
\hline 173.34 & 20.85 & 32.53 & 2014 \\
\hline 237.23 & 19.20 & 29.96 & 2015 \\
\hline 300.71 & 22.86 & 31.03 & 2016 \\
\hline 344.68 & 43.78 & 48.61 & 2017 \\
\hline 361.52 & 59.89 & 88.62 & 2018 \\
\hline 261.45 & 27.54 & 35.06 & المتوسط \\
\hline
\end{tabular}

المصدر : حسبت من البيانات الواردة بالجدول رقم (1).

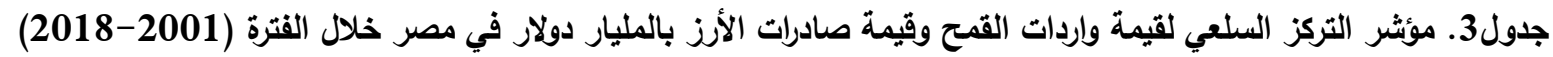

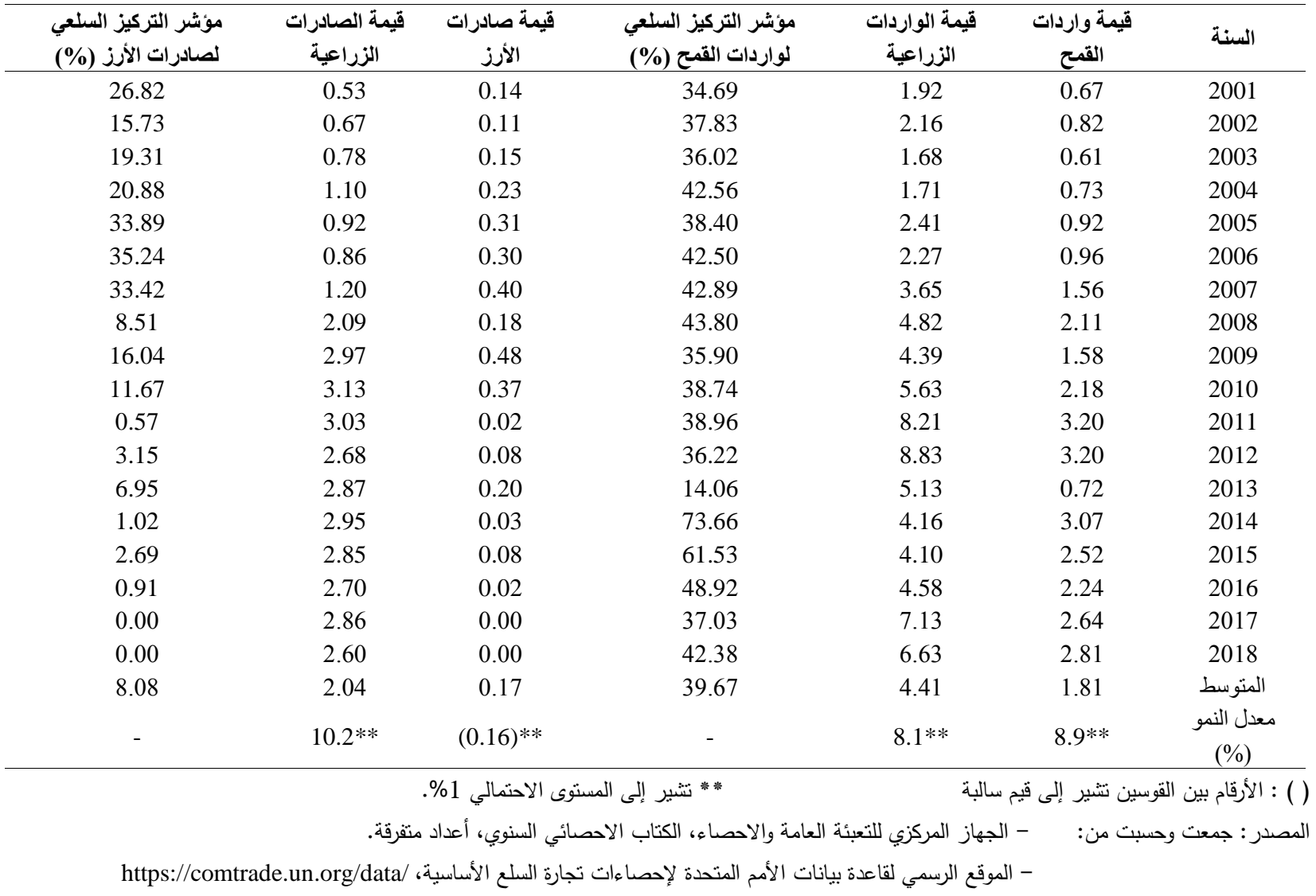




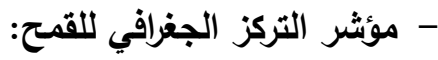
يضضح وجود تنذب في معاملات التزكز الجغرافي حيث تزاوح بين حد أدنى بلغ نحو $87.50 \%$ ندام أقصى بلغ نحو 85.50\% عام 2018 2018، بمنوسط هنسي

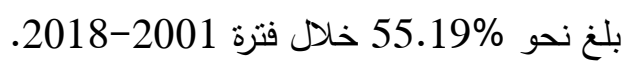

وبدراسة الأهمية النسبية لواردات مصر من القرة القمح أتضح

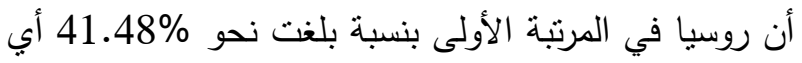

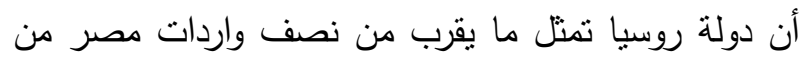

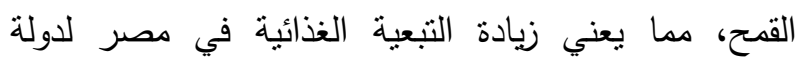

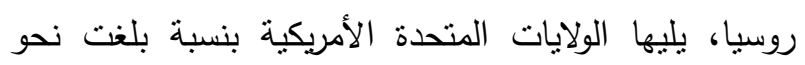

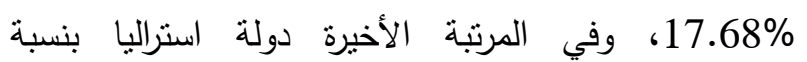

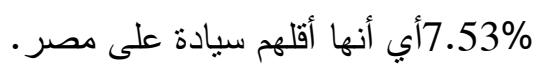

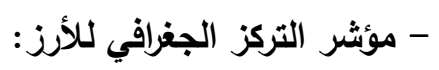

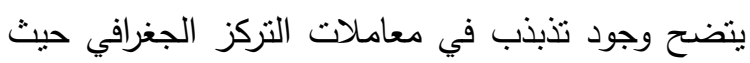

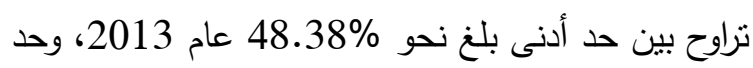

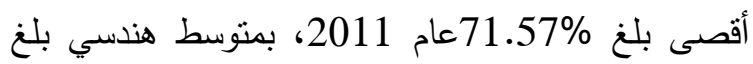

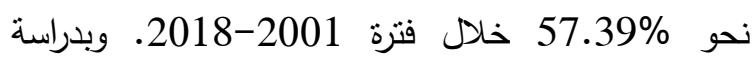
الأهمية النسبية لصادرات مصر من الأرز أتضح أن

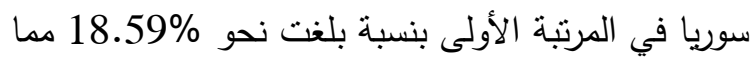

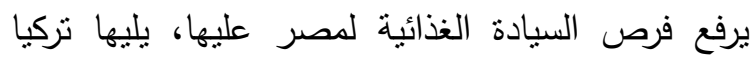
بنسبة بلغت نحو 11.97\%، وفي المرتبة الأخيرة دولة بلجيكا بنسبة 5.80\% أي أنها أقلهم تبعية غذائية لمصر

ومن خلال دراسة مؤشر التركز الجغرافي لحصصولي

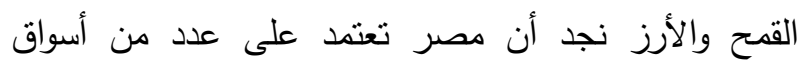
الاستيراد والتصدير وهذا ما يوضحه التززيع الجغرافي لواردات الترات القمح وصادرات الأرز لدول العالم كما بالثكل رقم (2)، رقم لألمرات
ويمكن التعرف على التبعية الغذائية لهاذين المحصولين من خلال:

\section{1-مؤشر التركز السلعي:}

- مؤثشر التركز السلعي لواردات القصح: تراوح مؤشر التركز

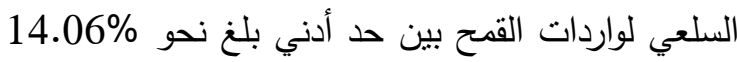

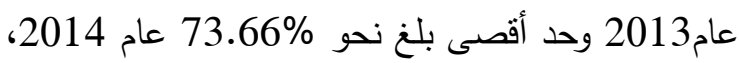
بمتوسط هندسي بلغ نحو 39.67\% خلا 2001-2018، مما بعني أن واردات القمح تستحوذ

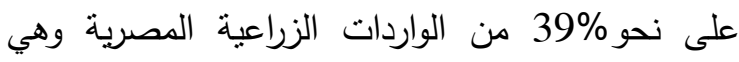

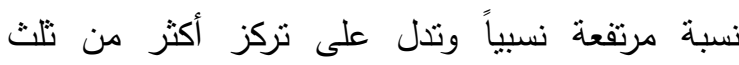

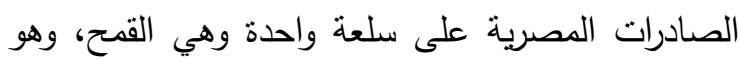

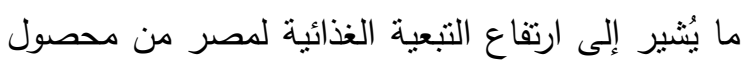
القمح.

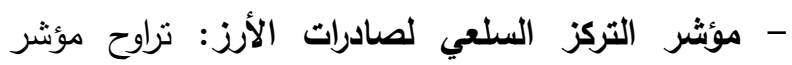
التركز السلعي لصادرات الأرز بين حد أدني بلغ نحو الهر 20.57\% عام 2011 وحد أقصى بلغ نحو $35.24 \%$ عام 2006، بمتوسط هندسي بلغ نحو 2018 208\% خلال

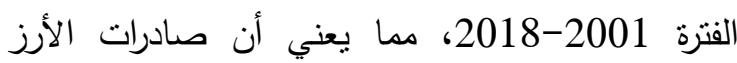
تساهم بنحو \% 80 من الصادرات الزراعية المصرية وهي

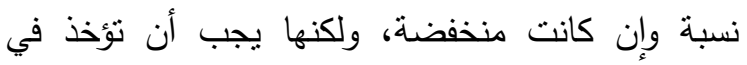

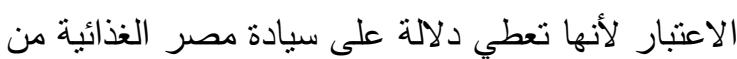

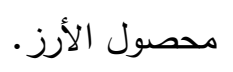

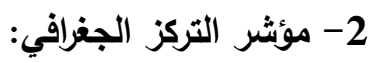

ويمكن التعرف على التبعية الغذائية لمحصول القمح او

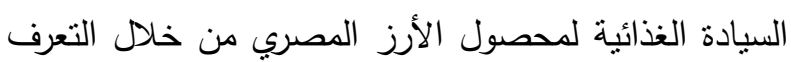
على التوزيع الجغرافي لهذين المحصولين كما بالجدول رقم

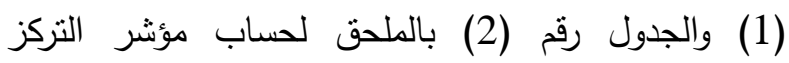
الجغرافي، واتضح من بيانات جدول رقم (4) و (5) ما يلي: 
جدول 4. مؤثر التركز الجغرافي لكمية واردات مصر من القمح بالمليون طن خلال الفترة (2001-2018)

\begin{tabular}{|c|c|c|c|c|c|c|c|}
\hline معامل التركز & دول أخرى & استراليا & اوكرانيا & فرنسا & الولايات المتحدة & روسيا & السنوات \\
\hline 59.51 & 0.0425 & 0.0283 & 0.0000 & 0.0096 & 0.2737 & 0.0000 & 2001 \\
\hline 45.47 & 0.0083 & 0.0276 & 0.0049 & 0.0238 & 0.1032 & 0.0389 & 2002 \\
\hline 49.55 & 0.0094 & 0.0075 & 0.0003 & 0.0466 & 0.1354 & 0.0463 & 2003 \\
\hline 51.05 & 0.0166 & 0.0557 & 0.0000 & 0.0120 & 0.1630 & 0.0134 & 2004 \\
\hline 50.40 & 0.0377 & 0.0145 & 0.0002 & 0.0097 & 0.0275 & 0.1644 & 2005 \\
\hline 46.08 & 0.0467 & 0.0276 & 0.0032 & 0.0079 & 0.0219 & 0.1051 & 2006 \\
\hline 54.38 & 0.0437 & 0.0023 & 0.0012 & 0.0004 & 0.0721 & 0.1760 & 2007 \\
\hline 49.60 & 0.0305 & 0.0011 & 0.0088 & 0.0060 & 0.0641 & 0.1355 & 2008 \\
\hline 51.12 & 0.0428 & 0.0020 & 0.0006 & 0.0483 & 0.0120 & 0.1556 & 2009 \\
\hline 47.71 & 0.0208 & 0.0035 & 0.0037 & 0.0724 & 0.0191 & 0.1082 & 2010 \\
\hline 50.85 & 0.0083 & 0.0093 & 0.0016 & 0.0109 & 0.0800 & 0.1485 & 2011 \\
\hline 58.60 & 0.0073 & 0.0013 & 0.0556 & 0.0026 & 0.0051 & 0.2716 & 2012 \\
\hline 70.34 & 0.2682 & 0.0000 & 0.0000 & 0.0000 & 0.2265 & 0.0000 & 2013 \\
\hline 50.40 & 0.0767 & 0.0000 & 0.0281 & 0.0361 & 0.0009 & 0.1122 & 2014 \\
\hline 59.93 & 0.0458 & 0.0003 & 0.0000 & 0.0428 & 0.0018 & 0.2685 & 2015 \\
\hline 60.11 & 0.0408 & 0.0001 & 0.0581 & 0.0013 & 0.0000 & 0.2611 & 2016 \\
\hline 64.83 & 0.0240 & 0.0002 & 0.0381 & 0.0003 & 0.0004 & 0.3573 & 2017 \\
\hline 87.50 & 0.0184 & 0.0000 & 0.0000 & 0.0000 & 0.0000 & 0.7473 & 2018 \\
\hline$* 55.19$ & 0.0438 & 0.0101 & 0.0114 & 0.0184 & 0.0670 & 0.1728 & المتوسط \\
\hline
\end{tabular}

جدول 5. مؤثر التركز الجغرافي لكمية صادرات مصر من الأز بالمليون طن خلال الفترة (2001-2016)

\begin{tabular}{|c|c|c|c|c|c|c|c|}
\hline معامل التركز الجغرافي & دول أخرى & بلجيكا & الاردن & ليبيا & تركيا & سوريا & السنوات \\
\hline 61.52 & 0.3205 & 0.0001 & 0.0011 & 0.0052 & 0.0186 & 0.0331 & 2001 \\
\hline 54.72 & 0.2271 & 0.0002 & 0.0117 & 0.0045 & 0.0258 & 0.0301 & 2002 \\
\hline 48.64 & 0.1191 & 0.0003 & 0.0055 & 0.0159 & 0.0507 & 0.0451 & 2003 \\
\hline 61.23 & 0.3063 & 0.0001 & 0.0036 & 0.0021 & 0.0101 & 0.0526 & 2004 \\
\hline 57.39 & 0.2620 & 0.0002 & 0.0022 & 0.0157 & 0.0123 & 0.0370 & 2005 \\
\hline 52.00 & 0.1917 & 0.0008 & 0.0145 & 0.0073 & 0.0174 & 0.0388 & 2006 \\
\hline 51.34 & 0.1901 & 0.0013 & 0.0091 & 0.0189 & 0.0163 & 0.0279 & 2007 \\
\hline 51.18 & 0.1791 & 0.0019 & 0.0034 & 0.0218 & 0.0167 & 0.0390 & 2008 \\
\hline 56.43 & 0.2473 & 0.0045 & 0.0037 & 0.0020 & 0.0118 & 0.0492 & 2009 \\
\hline 49.65 & 0.1159 & 0.0071 & 0.0001 & 0.0780 & 0.0102 & 0.0353 & 2010 \\
\hline 71.57 & 0.1269 & 0.3848 & 0.0000 & 0.0005 & 0.0000 & 0.0000 & 2011 \\
\hline 53.02 & 0.0986 & 0.1097 & 0.0001 & 0.0652 & 0.0000 & 0.0075 & 2012 \\
\hline 48.38 & 0.0985 & 0.0569 & 0.0004 & 0.0512 & 0.0017 & 0.0253 & 2013 \\
\hline 68.96 & 0.2109 & 0.2643 & 0.0002 & 0.0000 & 0.0001 & 0.0002 & 2014 \\
\hline 63.76 & 0.2633 & 0.1387 & 0.0000 & 0.0006 & 0.0004 & 0.0031 & 2015 \\
\hline 68.49 & 0.3992 & 0.0639 & 0.0000 & 0.0021 & 0.0000 & 0.0038 & 2016 \\
\hline 57.39 & 0.2098 & 0.0647 & 0.0040 & 0.0194 & 0.0128 & 0.0268 & المتوسط \\
\hline
\end{tabular}



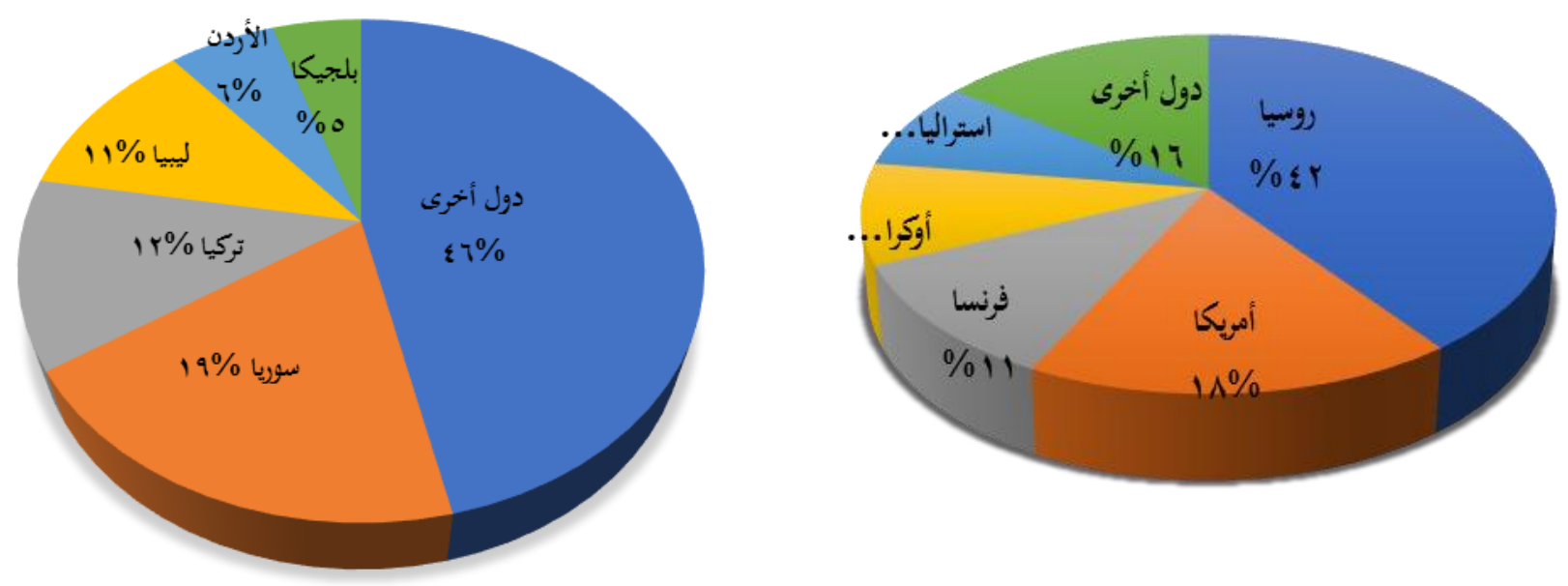

شكل 3. الأهمية النسبية للتوزيع الجغرافي لصادرات مصر من محصول الأز خلال القترة (2001-2016)

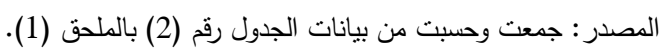
شكل 2. الأهمية النسبية للتوزيع الجغرافي لواردات مصر من محصول القمح خلال القترة (2001-2018) المصدر : جمعت وحسبت من بيانات الجدول رقم (1) بالملحق.

ومما سبق يمكن ان نخلص إلى أن تبعية مصر في القرارات الزراعية والتي يمكن تلخيصها في الثكل رقم (4) محصول القمح وسيادتها في محصول الأرز إلى سلسلة من والثكل رقم (5) فئل فئل زيادة المساحة المزروعة من القمح

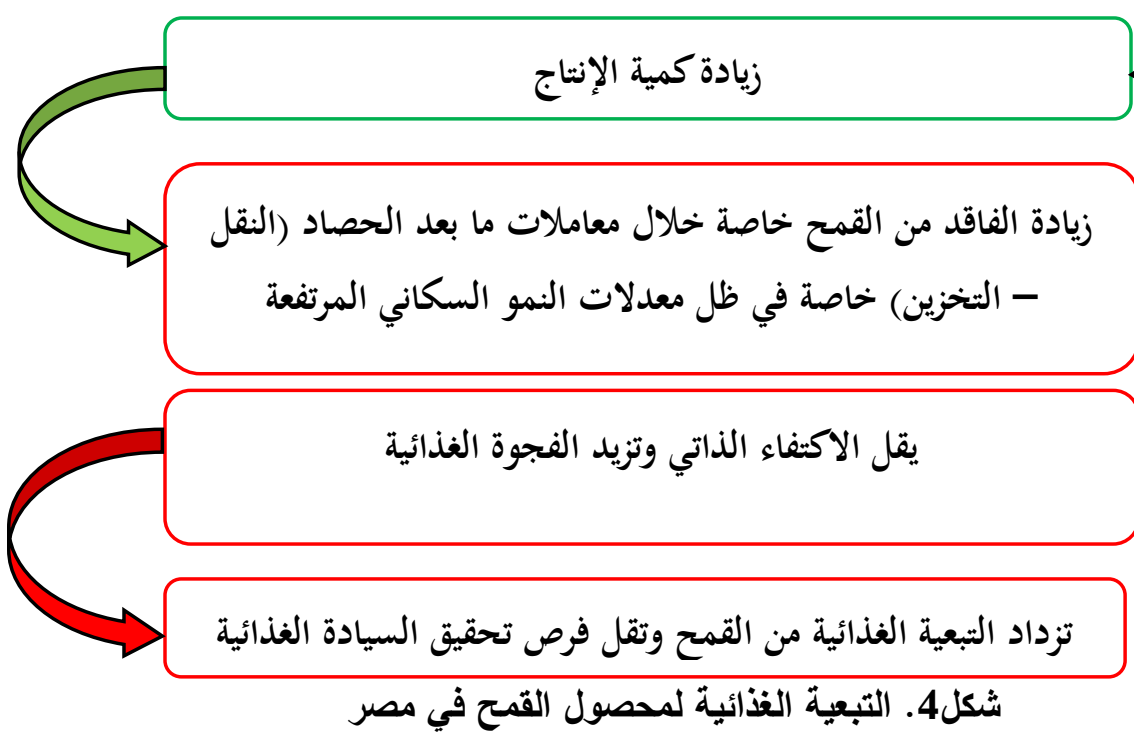




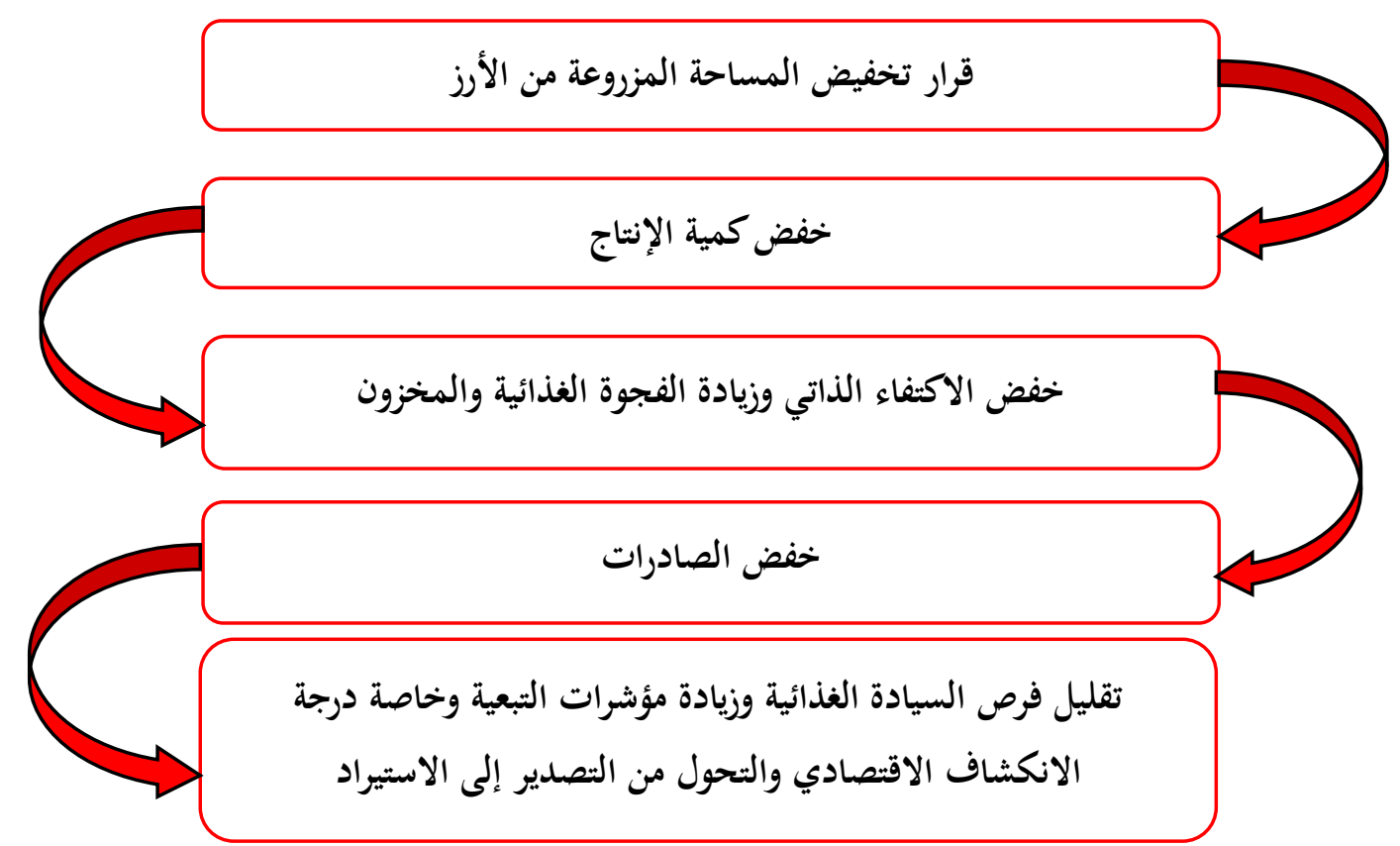

\section{شكل 5. السيادة الغذائية لمصصول الأزذ في مصر}

المصدر : إعداد الباحث

الجهاز المركزي للتعبئة العامة والاحصاء، الكتاب الاحصائي

السنوي، القاهرة، أعداد متفرقة.

عجمية، محمد عبد العزيز، وآخرون (2009)، التتمية الاقتصادية

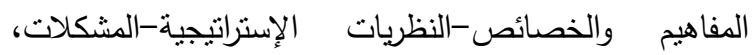

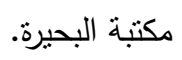

مختار ، سمر ثابت زاكي (2015)، السيادة الغذائية لأهم محاصيل

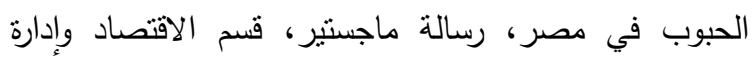
الأعمال الزراعية، كلية الزراعة، جامعة الإسكندرية.

مدياني محمد (2009)، دراسة قياسية للواردات في الجزائر خلا الفترة (1970- 2006)، رسالة ماجستير، كلية العلوم

$$
\text { الاقتصادية وعلوم التسيير، قسم العلوم الاقتصادية. }
$$

https://www.albankaldawli.org/الموقع الرسمي البنك الدولي،

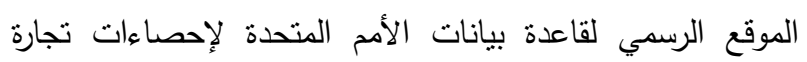

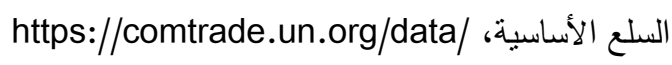
www.un.org/sustainable الموقع الرسمي لمنظمة الأمم المتحدة development goals

\section{المراجع}

الفيل، أحمد نوفيق، وآخرون (2014)، تحليل اقتصادي قياسي

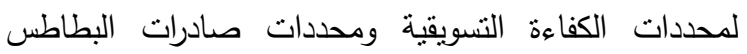

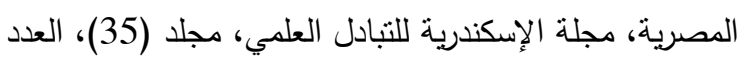

إسماعيل، علي، وعمران علي (2018)، قياس وتحليل أثز الانفتاح التجاري على بعض المتغيرات الاقتصادية في العراق للمدة (2003-2017)، مجلة جامعة كربلاء العلمية، المجلد

(16)، العدد (4) سليمان، أثرف (2018)، الاقتصاد السياسي للسيادة الغذائية في

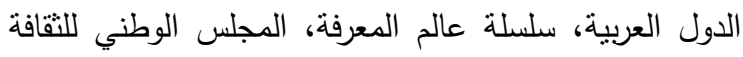

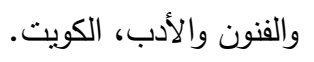

التطاوي، نشوي عبدالحميد، مرسي، مي مصطفي حسن

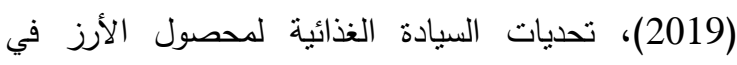
مصر، المؤتمر الدولي التاسع للتتمية الزراعية المنواصلة، كلية الزراعة، جامعة الفيوم، مارس. 


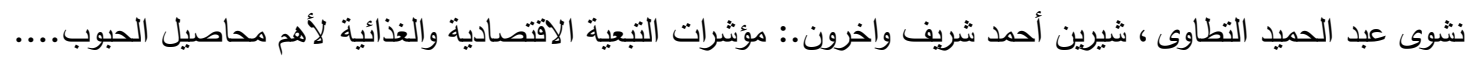

وزارة الزراعة واستصلاح الأراضي (2015)، استراتيجية التتمية

(2015)، استراتيجية التتمية

وزارة التخطبط والإصلاح الإداري

الزراعية المستدامة 2030، القاهرة.

المستدامة: روئة مصر 2030، القاهرة.

\title{
ABSTRACT \\ Indicators of Economic and Nutritional Dependence on the Most Important Grain Crops in Egypt
}

\author{
Nashwa EL-Tatawy, Sherin Sherif, Mai Mustafa Hassan Morsi, Samar Thabet
}

The features of economic and food dependence are evident in the wheat crop because of the food gap through import. As for the rice crop, the features of food sovereignty appear clearly, as Egypt achieves a food surplus from it and tends to export in small quantities. In the recent period, political decisions have affected on the trade and food balance of these two crops, which affected the indicators of dependency and food sovereignty for them, and accordingly; The research aims to detaect the food dependency of the most important grain crops in Egypt through indicators of economic, financial, and nutritional dependency in Egypt during the period 2001-2018, The research reached that wheat imports account for about 39\% of Egyptian agricultural imports, which is a high percentage and this is a bad indicator for the Egyptian economy, and Russia comes first with a percentage About $42 \%$ of Egypt's imports from the world amounted to nearly half of Egypt's imports from the world, which means that it increases Egypt's dependence on it, followed by the United States of
America and in the last place Australia. Rice exports also contribute about $8 \%$ of the Egyptian agricultural exports, which is a percentage, albeit low, but it must be considered. Syria comes in the first place with a rate of about 19\%, which means that it raises the chances of Egypt's sovereignty over it, followed by Turkey and in the last place is Belgium. The research recommends expanding the cultivation of land to increase the cultivated area of wheat, which helps to reduce the food gap and increase the rates of self-sufficiency, in order to reduce dependence on importing wheat and therefore reduce dependency on the wheat crop, the research also suggest rationing the consumption of rice to reduce economic dependence and achieve higher levels of food sovereignty, by reducing wastage rates of wheat and rice, especially during collection, packaging, transportation and storage.

KeyWords: Economic dependency- Food dependency - Wheat - Rice - food sovereignty. 


\section{المدحق}

جدول 1.الطاقة الاستيرادية والأهمية النسبية لأهم الدول المصدرة للقمح لمصر بالمليون طن خلال الفترة (2001-2018)

\begin{tabular}{|c|c|c|c|c|c|c|c|c|c|c|c|c|c|}
\hline$\%$ & أخرى & $\%$ & استراليا & $\%$ & اوكرانيا & $\%$ & فرنسا & $\%$ & المتحدة & $\%$ & روسيا & العالم & السنوات \\
\hline 20.61 & 0.91 & 16.81 & 0.74 & - & - & 9.81 & 0.43 & 52.32 & 2.31 & 0.45 & 0.02 & 4.41 & 2001 \\
\hline 9.11 & 0.51 & 16.62 & 0.93 & 0.02 & 0.39 & 15.44 & 0.86 & 32.12 & 1.80 & 19.73 & 1.10 & 5.60 & 2002 \\
\hline 9.71 & 0.39 & 8.66 & 0.35 & 0.00 & 0.07 & 21.60 & 0.87 & 36.80 & 1.49 & 21.52 & 0.87 & 4.04 & 2003 \\
\hline 12.88 & 0.56 & 23.60 & 1.03 & 0.00 & 0.03 & 10.93 & 0.48 & 40.37 & 1.76 & 11.56 & 0.50 & 4.36 & 2004 \\
\hline 19.43 & 1.11 & 12.04 & 0.69 & 0.00 & 0.09 & 9.83 & 0.56 & 16.58 & 0.94 & 40.54 & 2.31 & 5.69 & 2005 \\
\hline 21.60 & 1.26 & 16.60 & 0.97 & 0.02 & 0.33 & 8.91 & 0.52 & 14.79 & 0.86 & 32.42 & 1.89 & 5.81 & 2006 \\
\hline 20.90 & 1.25 & 4.84 & 0.29 & 0.01 & 0.20 & 2.02 & 0.12 & 26.86 & 1.60 & 41.95 & 2.50 & 5.96 & 2007 \\
\hline 17.47 & 0.69 & 3.24 & 0.13 & 0.02 & 0.37 & 7.76 & 0.31 & 25.32 & 1.00 & 36.82 & 1.46 & 3.97 & 2008 \\
\hline 20.68 & 0.84 & 4.49 & 0.18 & 0.00 & 0.10 & 21.98 & 0.89 & 10.96 & 0.44 & 39.45 & 1.60 & 4.05 & 2009 \\
\hline 14.41 & 1.43 & 5.91 & 0.59 & 0.03 & 0.60 & 26.90 & 2.67 & 13.82 & 1.37 & 32.89 & 3.26 & 9.92 & 2010 \\
\hline 9.09 & 0.89 & 9.67 & 0.95 & 0.02 & 0.39 & 10.44 & 1.02 & 28.28 & 2.77 & 38.54 & 3.78 & 9.80 & 2011 \\
\hline 8.55 & 0.71 & 3.57 & 0.29 & 0.10 & 1.94 & 5.06 & 0.42 & 7.13 & 0.59 & 52.12 & 4.30 & 8.25 & 2012 \\
\hline 51.74 & 0.06 & 0.05 & 0.00 & 0.00 & 0.00 & 0.42 & 0.00 & 47.59 & 0.06 & 0.20 & 0.00 & 0.12 & 2013 \\
\hline 27.68 & 0.35 & 0.01 & 0.00 & 0.01 & 0.21 & 19.00 & 0.24 & 3.04 & 0.04 & 33.50 & 0.42 & 1.25 & 2014 \\
\hline 0.00 & 0.00 & 0.00 & 0.00 & 0.00 & 0.00 & 0.00 & 0.00 & 0.00 & 0.00 & 0.00 & 0.00 & 0.00 & 2015 \\
\hline 20.19 & 0.95 & 1.00 & 0.05 & 0.06 & 1.14 & 3.60 & 0.17 & 0.00 & 0.00 & 51.10 & 2.41 & 4.72 & 2016 \\
\hline 15.49 & 1.69 & 1.54 & 0.17 & 0.11 & 2.13 & 1.66 & 0.18 & 2.01 & 0.22 & 59.78 & 6.51 & 10.89 & 2017 \\
\hline 13.55 & 1.18 & 0.00 & 0.00 & 0.00 & 0.00 & 0.00 & 0.00 & 0.00 & 0.00 & 86.45 & 7.54 & 8.73 & 2018 \\
\hline 15.14 & 0.82 & 7.53 & 0.41 & 8.68 & 0.47 & 9.98 & 0.54 & 17.68 & 0.96 & 41.48 & 2.25 & 5.42 & المتوسط \\
\hline
\end{tabular}


نشوى عبد الحميد التطاوى ، شيرين أحمد شريف واخرون.: مؤشرات التبعية الاقتصادية والغذائية لأهم محاصيل الحبوب.... 31

جدول 2. الطاقة التصديرية والأهمية النسبية لأهم الدول المستوردة للأز المصري بالمليون طن خلال الفترة (2001-

(2016

\begin{tabular}{|c|c|c|c|c|c|c|c|c|c|c|c|c|c|}
\hline$\%$ & أخرى & $\%$ & بلجيكا & $\%$ & الأردن & $\%$ & ليبيا & $\%$ & تركيا & $\%$ & سوريا & العالم & السنوات \\
\hline 56.61 & 401.22 & 1.11 & 7.90 & 3.28 & 23.22 & 7.19 & 50.92 & 13.62 & 96.55 & 18.19 & 128.89 & 708.70 & 2001 \\
\hline 47.66 & 228.83 & 1.39 & 6.66 & 10.82 & 51.97 & 6.72 & 32.27 & 16.07 & 77.14 & 17.34 & 83.28 & 480.16 & 2002 \\
\hline 34.51 & 202.35 & 1.72 & 10.10 & 7.41 & 43.47 & 12.60 & 73.87 & 22.51 & 131.95 & 21.24 & 124.54 & 586.26 & 2003 \\
\hline 55.34 & 465.67 & 1.03 & 8.68 & 6.01 & 50.58 & 4.62 & 38.84 & 10.06 & 84.66 & 22.94 & 193.01 & 841.45 & 2004 \\
\hline 51.19 & 569.64 & 1.28 & 14.22 & 4.69 & 52.15 & 12.52 & 139.38 & 11.08 & 123.30 & 19.25 & 214.20 & $1,112.89$ & 2005 \\
\hline 43.78 & 430.53 & 2.78 & 27.33 & 12.02 & 118.21 & 8.53 & 83.88 & 13.18 & 129.63 & 19.71 & 193.78 & 983.37 & 2006 \\
\hline 43.60 & 533.47 & 3.64 & 44.52 & 9.53 & 116.58 & 13.76 & 168.41 & 12.77 & 156.29 & 16.70 & 204.33 & $1,223.61$ & 2007 \\
\hline 42.32 & 151.55 & 4.40 & 15.76 & 5.83 & 20.89 & 14.76 & 52.87 & 12.93 & 46.32 & 19.75 & 70.71 & 358.11 & 2008 \\
\hline 49.73 & 323.90 & 6.73 & 43.86 & 6.08 & 39.63 & 4.44 & 28.91 & 10.84 & 70.64 & 22.17 & 144.43 & 651.38 & 2009 \\
\hline 34.04 & 195.10 & 8.42 & 48.23 & 0.72 & 4.10 & 27.92 & 160.02 & 10.10 & 57.90 & 18.80 & 107.74 & 573.08 & 2010 \\
\hline 35.63 & 15.24 & 62.03 & 26.53 & 0.00 & - & 2.34 & 1.00 & 0.00 & - & 0.00 & 0.00 & 42.77 & 2011 \\
\hline 31.40 & 39.24 & 33.12 & 41.38 & 0.77 & 0.97 & 25.54 & 31.91 & 0.49 & 0.61 & 8.68 & 10.85 & 124.95 & 2012 \\
\hline 31.38 & 105.57 & 23.86 & 80.25 & 2.10 & 7.06 & 22.62 & 76.10 & 4.12 & 13.87 & 15.91 & 53.53 & 336.39 & 2013 \\
\hline 45.93 & 37.74 & 51.41 & 42.24 & 0.00 & - & 0.00 & - & 1.14 & 0.94 & 1.52 & 1.25 & 82.16 & 2014 \\
\hline 51.31 & 69.99 & 37.25 & 50.80 & 0.80 & 1.10 & 2.78 & 3.79 & 2.12 & 2.89 & 5.74 & 7.83 & 136.39 & 2015 \\
\hline 63.18 & 31.05 & 25.29 & 12.43 & 0.62 & 0.31 & 4.56 & 2.24 & 0.15 & 0.07 & 6.20 & 3.05 & 49.14 & 2016 \\
\hline 45.85 & 237.57 & 5.80 & 30.06 & 6.40 & 33.14 & 11.39 & 59.03 & 11.97 & 62.05 & 18.59 & 96.34 & 518.18 & المتوسط \\
\hline
\end{tabular}

